\title{
VIII. On the comet of 1825
}

\section{Thomas Squire Esq.}

To cite this article: Thomas Squire Esq. (1826) VIII. On the comet of 1825, Philosophical Magazine Series 1, 67:333, 55-56, DOI: $10.1080 / 14786442608674012$

To link to this article: http://dx.doi.org/10.1080/14786442608674012

曲 Published online: 10 Aug 2009.

Submit your article to this journal $\pi$

LII Article views: 2

Q View related articles $₫$ 
question merely for the sake of victory, and too candid to hesitate a single moment in expressing my conviction, whatever may have been my previous opinions, or however my credit may seem to be pledged in their support.

Bath, Dec. 5, 1825.

VIII. On the Comet of 1825. By Thomas Squire, Esq.

\section{To the Editor of the Philosophical Magazine and Journal.} Sir,

WITHOUT entering into the nature of those chaotic compounds of elementary substances, or rather incipient worlds called comets, of which we, perhaps, are less acquainted than with their motions; yet, nevertheless, $I$ think it may truly be said that no part of astronomy is more in its infancy than that which relates to the eccentric and anomalous motions of these erratic bodies, which are occasionally and at very uncertain periods observed to visit the bounds of our solar system, when passing through the perihelion parts of their orbits.

Should you, Mr. Editor, think the following computations and remarks, which relate to the comet of 1825 (that first appeared about the beginning of September), entitled to a place in your scientific Journal, they are truly at your service.

On the supposition of a parabolic orbit, this comet must have passed from the northern to the southern side of the ecliptic about the 22d of August; but it was not visible to the naked eye until the 7th of September, when it was seen in the constellation Taurus, near Aldebaran and the Hyades; at which time its distance from the sun was 1.871 , and from the earth $1 \cdot 407$. On the 12 th of the same month at 1 A.M. its anomaly was $69^{\circ} 34^{\prime} 38^{\prime \prime}$, its distance from the sun $1 \cdot 8229$, and from the earth $1 \cdot 2391$, having also a geocentric longitude of $60^{\circ} 40^{\prime} 19^{\prime \prime}$, and a southern latitude of $6^{\circ} 34^{\prime} 29^{\prime \prime}$. Again, on the 17th, the comet's distance from the sun was $1 \cdot 767$, and from the earth $1 \cdot 105$. It continued thus to approach the earth in a lateral direction till the 12th of October, when by computation it appears to have come nearest to the earth, at which time it was a very conspicuous object in the heavens; when, at midnight, its distance from the sun was $1 \cdot 525756$, and from the earth only 61471 : its geocentric longitude was $35^{\circ} 8^{\prime} 11^{\prime \prime}$, and latitude $35^{\circ} 51^{\prime} 35^{\prime \prime}$ south. Hence it was then in the southern part of the constellation Cetus. Therefore at this time it must have been vertical between the parallels of 20 and 21 degrees south, a little before two o'clock that morning, according to 
the respective meridians. From this it is clear that the comet must have been a very striking object to all the known parts of the southern hemisphere and the low northern latitudes. After the 12th of October the earth and comet gradually receded from each other, so that on or about the 17th of November the comet must have been too far from the earth to be visible, even under the most favourable circumstances of southern latitude. Although the relative motions of the earth and comet were now such as rapidly to increase their lineal distance, yet the comet continued to approach the sun till the 11 th of December, when it passed its perihelion point at a distance of 1.2295 from that body.

The earth and comet will continue to recede from each other till about the 20th of January; and as the heliocentric motion of the latter body is retrograde, and being at the same time in an opposite part of the heavens in respect to the earth, the two bodies will for some time move nearly parallel to each other, and towards the same infinite distant point in space, when the comet's distance from the sun will be 1.4 , and from the earth $2 \cdot 28$, the latter distance being equal to 21660 millions of miles. Though the orbicular motion of the comet will now carry it rapidly from the sun, yet it will again gradually approach the earth, or more properly, the earth may be said in the race to gain upon the comet till about the $22 \mathrm{~d}$ of April; and on that day, at $5^{\mathrm{h}} 49=12^{\mathrm{s}} \mathrm{M}$.T. its distance from the sun will be $2 \cdot 27056$, and from the earth 1.37183, having at the same time a geocentric longitude of $24.3^{\circ} 49^{\prime} 46^{\prime \prime}$, and a southern latitude of $15^{\circ} 27^{\prime} 56^{\prime \prime}$ : hence it will be near the star $\checkmark$ in the neck of the constellation Lupus; at which time, and for a few days before and after, it may again be expected to be visible to the southern parts of the world, but its altitude above our horizon will be too small for it to be seen from our northern position; and by the beginning of May it will be too far from the sun and from the earth to admit of its being any longer visible to the inhabitants of our globe. On the second appearance of this comet it will, properly speaking, be divested of its tail; in which case the nucleus will only be surrounded by a nebulous light.

Epping, Jan. 1, 1826. Yours respectfully,

P.S. It is a little remarkable that the comet of 1823 passed its perihelion about the same time in December as that of 1825 ; but the former when in that point of its orbit was nearly at the same distance from the sun, as the latter was beyond the sphere of the earth's orbit, their relative perihelion distances being $\cdot 228944$ and $1 \cdot 229.50$ respectively. 